\title{
Enhancement in corrosion resistance and vibration damping performance in titanium by titanium nitride coating
}

\author{
Kaushik Sarkar ${ }^{1} \cdot$ Panupong Jaipan ${ }^{1} \cdot$ Jonghyun $\mathrm{Choi}^{2} \cdot$ Talisha Haywood $^{1} \cdot$ Duy Tran $^{1} \cdot$ Nikhil Reddy Mucha $^{1}$. \\ Sergey Yarmolenko ${ }^{1}$. Onome Scott-Emuakpor ${ }^{3} \cdot$ Mannur Sundaresan $^{1} \cdot$ Ram K. Gupta $^{2} \cdot$ Dhananjay Kumar $^{1}$ (D)
}

Received: 27 January 2020 / Accepted: 15 April 2020 / Published online: 23 April 2020

(c) Springer Nature Switzerland AG 2020

\begin{abstract}
Titanium nitride (TiN) thin films are deposited on titanium (Ti) substrates by pulsed laser deposition and radio frequency magnetron sputtering. The main goal of this research is to improve the corrosion resistance and the vibration damping performance of the Ti substrates by surface modification of the substrates with TiN thin film coatings. Electrochemical results indicate that TiN films bring about a significant improvement in the corrosion resistance of the Ti disks in phosphate buffer saline solution. It is also observed that TiN deposited at room temperature has the best corrosion efficiency in terms of lower corrosion current density and more positive corrosion potential. From the damping measurements, it is observed that the damping ratios of the TiN-coated beams are one to two orders of magnitude greater than those of uncoated ones. Additionally, the damping amplitudes of the TiN coated beams have been observed to return to zero position faster than the uncoated beam. The energy dissipation due to internal friction at the beam-coating interface and inter-lamellae interface within TiN coatings can be the mechanism responsible for reducing vibration amplitudes of TiN-coated beams.
\end{abstract}

Keywords Titanium nitride film · Polarization · Electrochemical impedance spectroscopy · Vibration damping $\cdot \mathrm{RF}$ magnetron sputtering $\cdot$ Pulsed laser deposition

\section{Introduction}

Vibration fatigue failures of the components have become a central problem in the aerospace industry $[1,2]$. The principal cause of the failure arising from the vibrations in aircraft engine components is considered as high cycle fatigue (HCF) [1-5]. The HCF fatigue can cause unpredictable catastrophes in engine turbine blades as a result of the effect of high-frequency vibratory loading [6]. Currently, researchers are focusing on surface modification with the aid of hard coating materials as one of the potential means to reduce this fatiguefailure in the aircraft engine components [1, 2, 5, 7-9].
When applied on the surface of components, hard coating can reduce resonant vibration levels by absorbing or dissipating energy and increasing the fatigue life of the components. The energy absorption/dissipation process is originated at internal defects, intergranular and substrate-coating interfaces, and dislocation motion [1, $10,11]$. Popular damping material, such as viscoelastic polymers, has temperature limitation and low stability in harsh working conditions [2]. Since the vibration dissipation mechanism does not depend only on the viscoelasticity, more thermally stable materials can be used as a suitable damper [12]. Some of the popular hard coating materials are $8 \mathrm{wt} \%$ Yttiria stabilized zirconia (YSZ) [11,

Dhananjay Kumar, dkumar@ncat.edu | 'Department of Mechanical Engineering, North Carolina Agricultural and Technical State University, Greensboro, NC 27411, USA. ${ }^{2}$ Department of Chemistry, Pittsburg State University, Pittsburg, KS 66762, USA. ${ }^{3}$ Aerospace Systems Directorate (AFRL/RQTI), Wright-Patterson AFB, OH 45433, USA. 
13], polycrystalline alumina coating, NiCrAIY, FeCrAIY [8, $14,15]$ and Magnesium aluminate spinel $\left(\mathrm{MgO}+\mathrm{Al}_{2} \mathrm{O}_{3}\right)$ [3]. Torvik et al. have compared the damping performance of magnetoelastic materials and plasma sprayed ceramic with a viscoelastic infiltrate [8]. Tassini et al. compared the damping and stiffness properties of $8 \mathrm{wt} \%$ yttria-stabilized zirconia ceramic coating deposited by arc plasma spraying and electron beam-physical vapor deposition [16]. Du et al. evaluated better damping performance of ZrTiN on TC4 titanium alloy [2].

Interestingly, transition metal nitrides such as TiN, ZrN, and TiZrN are emerging as attractive coating materials to mitigate damping problems due to their high hardness, high thermal and chemical stability and low electrical resistivity. The requirements of high strength, excellent corrosion resistance and high operating temperature in the aerospace industry have made titanium and its alloys more suitable over steel and aluminum [17]. The density of titanium alloys $\left(\sim 4.5 \mathrm{~g} \mathrm{~cm}^{-3}\right)$ is about half of Ni-based superalloys $\left(\sim 8.9 \mathrm{~g} \mathrm{~cm}^{-3}\right)$. With an excellent strength-toweight ratio and exceptional corrosion resistance, the use of titanium alloys in the aerospace sector is frequent in airframe, engine, helicopter, and space applications [18]. The use of titanium alloys is comparatively greater in military aircraft than commercial ones. Some of the military aircraft can contain up to $50 \%$ of its fuselage made of titanium alloys. Particularly, TiN films exhibit excellent mechanical properties such as high hardness, wear resistance, high thermal stability, and high chemical stability [19-24]. Additionally, TiN thin films are used in many industrial sectors due to its high abrasion resistance, low friction coefficient [25]. Titanium nitride coatings are also widely used to enhance functional properties such as lubricity, biocompatibility and antimicrobial effect for medical devices and surgical tools due to its low modulus, good fatigue strength, formability, machinability, corrosion resistance and biocompatibility [26-29]. Scientists have used many different hard coatings for damping treatments based on titanium alloys, only a few of them studied the feasibility of titanium nitride (TiN) as suitable damping materials. Plus, the materials science perspectives of the TiN coatings for vibration damping are still not well-understood. Moreover, a thin coating layer is a high demand in the aerospace industry to provide corrosion protection and improve adhesion between the substrate and the primer of the aircraft components [30]. The aerospace industry has, therefore, shown their interest in developing new coating layers to prevent the aircraft components from corrosion [30]. So, a detailed study on the corrosion resistance of TiN coating is important. The primary objective of the current work was to demonstrate the unique capability of TiN thin-film coatings to favorably affect two of many important requirements for enhancing the lifecycle of engine components: (a) decrease corrosion and (b) suppress fatigue-failure due to vibration.

\section{Experimental methods}

\subsection{Thin-film depositions}

We have used two physical vapor deposition-based methods for depositing TiN thin film coatings on the Ti substrates: pulsed laser deposition (PLD) and radio frequency (RF) magnetron sputtering. As RF magnetron sputtering is a very convenient technique to make thicker films in relatively shorter times and due to higher film thickness requirements in vibration damping testing, all the films used in the vibration damping experiments were made by the RF magnetron sputtering. Our methods for structural and surface morphology characterizations included X-ray diffraction (XRD) and scanning electron microscopy (SEM). The methods for mechanical and corrosion tests included nanoindentation, adhesion, potentiodynamic polarization, and electrochemical impedance spectroscopy. Lastly, the vibration damping performance testing was conducted by using an oscilloscope interfaced with a wave generator.

\subsubsection{Pulsed laser deposition for coating titanium nitride thin films}

A pure titanium rod with $\sim 10 \mathrm{~mm}$ diameter was cut into disks with a thickness of approximately $1 \mathrm{~mm}$ each. Before depositions, all substrates were polished with a mechanical polisher-grinder using $\mathrm{SiC}$ sandpaper up to 1200 grit. The polished Ti disk-shaped substrates were cleaned in acetone and ethanol using an ultrasonic cleaner. The substrates were also vapor cleaned from a heated beaker of acetone before being mounted onto the substrate heater of the PLD system. A thin layer of silver paste was applied to the heater, and then the substrates were placed on top of the paste to secure them from falling off during the depositions. The krypton fluoride (KrF) excimer laser (Lambda Physik) with a radiation wavelength of $248 \mathrm{~nm}$ and a pulse duration of $30 \mathrm{~ns}$ was used to deposit TiN films on pure titanium (Ti) substrates. A 99.9\% pure composite titanium nitride target was ablated with a target-to-substrate distance of $4 \mathrm{~cm}$. Three different substrate temperatures starting from room temperature $\left(\mathrm{RT}, \sim 30^{\circ} \mathrm{C}\right)$ to $600^{\circ} \mathrm{C}$ and $750^{\circ} \mathrm{C}$ were used for TiN depositions at approximately $10^{-6}$ Torr. Constant laser fluence $2.36 \mathrm{~J} \mathrm{~cm}^{-2}$ with a repetition rate of $10 \mathrm{~Hz}$ was maintained for all depositions. Then, next to study the effect of the presence of nitrogen gas on TiN growth, nitrogen pressure was fed into the vacuum chamber and the depositions were done in 50 mTorr and 100 mTorr of nitrogen while the temperature was fixed at 
$600{ }^{\circ} \mathrm{C}$ and other parameters were kept constant for all depositions. Note that 10,000 laser pulses were used to deposit the films for XRD and surface morphology studies, and 30,000 laser pulses were used to produce the films for mechanical testing (hardness) and corrosion resistance studies. For XRD characterization, an AXS D8 discover series with a Bruker monochromatic Cu Ka source of wavelength $\lambda=0.1545 \mathrm{~nm}$ and with the scan speed of $0.8 \mathrm{~s} / \mathrm{step}$ and the increment of 0.01426 degrees, was used for this study.

\subsubsection{RF magnetron sputtering for coating titanium nitride thin films}

A $10 \mathrm{~cm} \times 10 \mathrm{~cm} \times 0.1 \mathrm{~cm}$ titanium plate was cut into $5 \mathrm{~cm} \times 1 \mathrm{~cm} \times 0.1 \mathrm{~cm}$ rectangular beams by using a laser cutting tool. The reason behind using a beam shaped substrate was because of the cantilever boundary condition requirement for the vibration damping test. Then, all $5 \mathrm{~cm} \times 1 \mathrm{~cm} \times 0.1 \mathrm{~cm}$ beams were polished with 600,800 , and 1200 grit SiC sandpaper. The polished beams were cleaned with acetone and ethanol before the depositions with magnetron sputtering. Titanium nitride coatings were deposited on three Ti beams under three conditions. Two of the Ti beams were coated at $300^{\circ} \mathrm{C}$ and 2 mTorr nitrogen/Ar ambient for two different times of $1.5 \mathrm{~h}$ and $3 \mathrm{~h}$. The third Ti beam was coated with at $300^{\circ} \mathrm{C}$ and 2 mTorr nitrogen/Ar ambient for $3 \mathrm{~h}$ with a Ti metal film coating prior to the TiN deposition. A Ti metal film was deposited under the same deposition conditions for $10 \mathrm{~min}$. The purpose of Ti metal film deposition was to increase the adhesion of TiN films on the Ti beams. The power of 350 Watts DC and 8 Watts RF, the working distance of $85 \mathrm{~cm}$, $20 \mathrm{sccm}$ Ar flow rate, and $6.8 \mathrm{sccm}$ nitrogen flow rate were used and maintained for all three depositions. Then, after the depositions, we performed damping measurements to observe their damping characteristics for vibration suppression of the titanium beams. Lastly, we observed the microstructure and surface morphology of the beams by using a scanning electron microscope (SU8000 SEM, Hitachi ${ }^{\circ}$, and the thicknesses of the beams were determined by using Image Pro+.

\subsection{Mechanical characterization by nanoindentation}

Nanoindentation is an ideal hardness test for thin films because low indentation depths can be achieved using a nano-sized diamond tip. The standard Berkovich nanoindenter was used for the load-displacement nanoindentation curve. The loading and unloading were recorded continuously at least ten places of the sample to avoid erroneous results of hardness. The load-displacement data are analyzed for hardness and modulus measurements. Stiffness, $S$, is calculated from the unloading portion of the load-displacement data as follows:

$S=\frac{d P}{d h}=\frac{2}{\sqrt{\pi}} E_{r} \sqrt{A}$

$S=d P / d h$ is the experimentally measured stiffness of the upper portion of the unloading data, $A$ is the projected area of the elastic contact, and $E_{r}$ is the reduced modulus defined by the equation,

$\frac{1}{E_{r}}=\frac{1-v^{2}}{E}+\frac{1-v_{i}^{2}}{E_{i}}$

where $E$ and $v$ are Young's modulus and Poisson's ratio for the specimen and $E_{i}$ and $v_{i}$ are the same parameters for the indenter. By measuring initial unloading stiffness, the modulus is calculated using Eqs. (1) and (2).

\subsection{Potentiodynamic polarization measurements}

Potentiodynamic polarization measurements were carried out for determining corrosion resistance using an electrochemical cell set-up shown schematically in Fig. 1. The experiments were conducted using a Gamry Potentiostat (R600, Gamry Instruments). The standard threeelectrode configuration consisted of a standard silversilver chloride $(\mathrm{Ag} / \mathrm{AgCl})$ electrode, which was used as the reference electrode, a platinum $(\mathrm{Pt})$ counter electrode and a TiN-coated sample of interest acted as a working electrode. Before conducting the experiments, the samples were immersed in the test solution for about 10 min until steady-state conditions were achieved. All of the potentiodynamic polarization measurements were performed

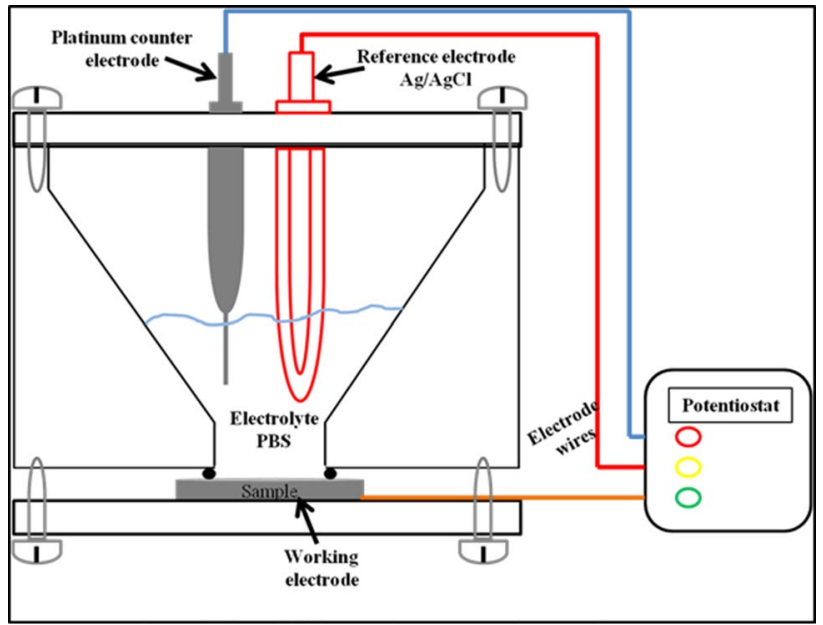

Fig. 1 Experimental setup for electrochemical corrosion testing 
in phosphate-buffered saline (PBS) solution containing 155.17 mM Sodium Chloride, 1.05 mM Potassium Phosphate monobasic, and $2.97 \mathrm{mM}$ Sodium Phosphate dibasic ( $\mathrm{pH}=7.4,1 \mathrm{X}$ working concentration) at room temperature. The scan rate was set at $5 \mathrm{mV} / \mathrm{s}$ spanning a scan range of $\pm 0.3 \mathrm{~V}$ versus an open circuit potential $\left(E_{o c}\right)$. The data are plotted as potential versus current density.

\subsection{Vibration damping measurements}

An oscilloscope (Wavejet 314, LeCroy) interfaced with a wave generator (33220A, Agilent) was used to measure the damping performances of the samples where PZT sensors with a dimension of $5 \mathrm{~mm} \times 5 \mathrm{~mm}$ were glued on the top and the bottom of the samples, as shown schematically in Fig. 2. Electrical contacts were made to the top and bottom sensors for input and output signals, respectively. Then, each beam was fixed at the sample holder prior to inducing waveform force. The input of the sine waves with the frequency of $235 \mathrm{~Hz}, 10 \mathrm{Vpp}$, and 3 cycles was generated by a waveform generator to induce the vibration on these samples. The uncoated, $1.5 \mathrm{~h}$ coated TiN, $3 \mathrm{~h}$ coated TiN, and $3 \mathrm{~h}$ coated $\mathrm{TiN}+10 \mathrm{~min}$ Ti layer samples are labeled as Ti0TiN, Ti90TiN, Ti180TiN, and Ti180TiN ${ }^{+}$, respectively. Then, damping performance recorded on the oscilloscope after inducing vibration in each beam was determined and the damping measurement was performed five times on each sample.

\section{Results and discussions}

\subsection{Structural characterization}

Figure 3 shows the XRD patterns for pulsed laser deposited TiN thin films grown on titanium substrates in a vacuum $\left(\sim 4-5 \times 10^{-6} \mathrm{Torr}\right)$ at room temperature $\left(\sim 30^{\circ} \mathrm{C}\right)$, $600^{\circ} \mathrm{C}$ and $750^{\circ} \mathrm{C}$. These XRD patterns indicate that the TiN thin films are polycrystalline with mixed (hkl) planes such as (111), (200), (311), and (222). The d-values of these planes correspond to the face-centered rock salt type crystal structures of the $\mathrm{TiN}$, which are in agreement with JCP2.2CA:00-038-1420 (TiN) from the International Centre for Diffraction Data (ICDD) card. It can be observed from Fig. 3 that (200) is the preferred orientation for samples deposited in a vacuum as well as nitrogen ambient at room

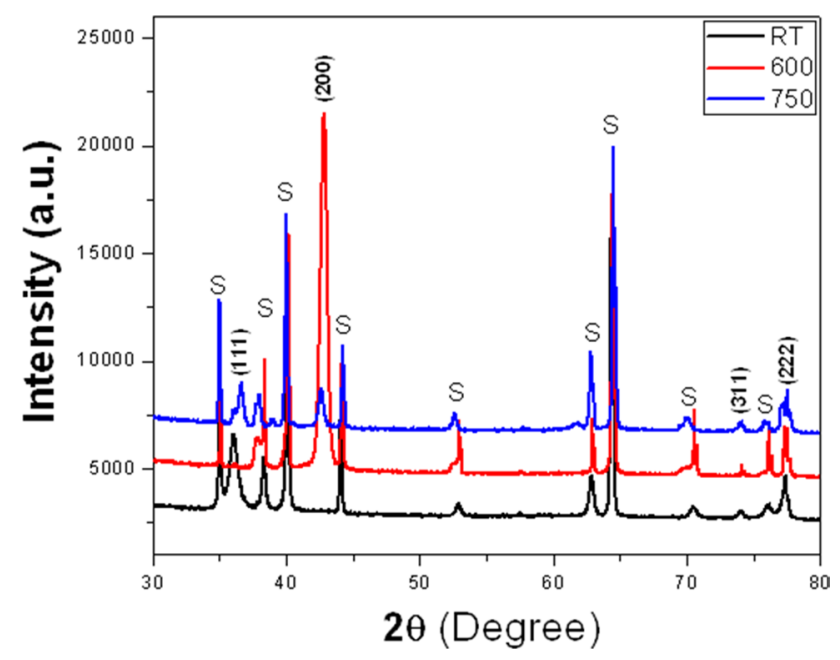

Fig. 3 XRD pattern for TiN grown on titanium disks at different temperatures

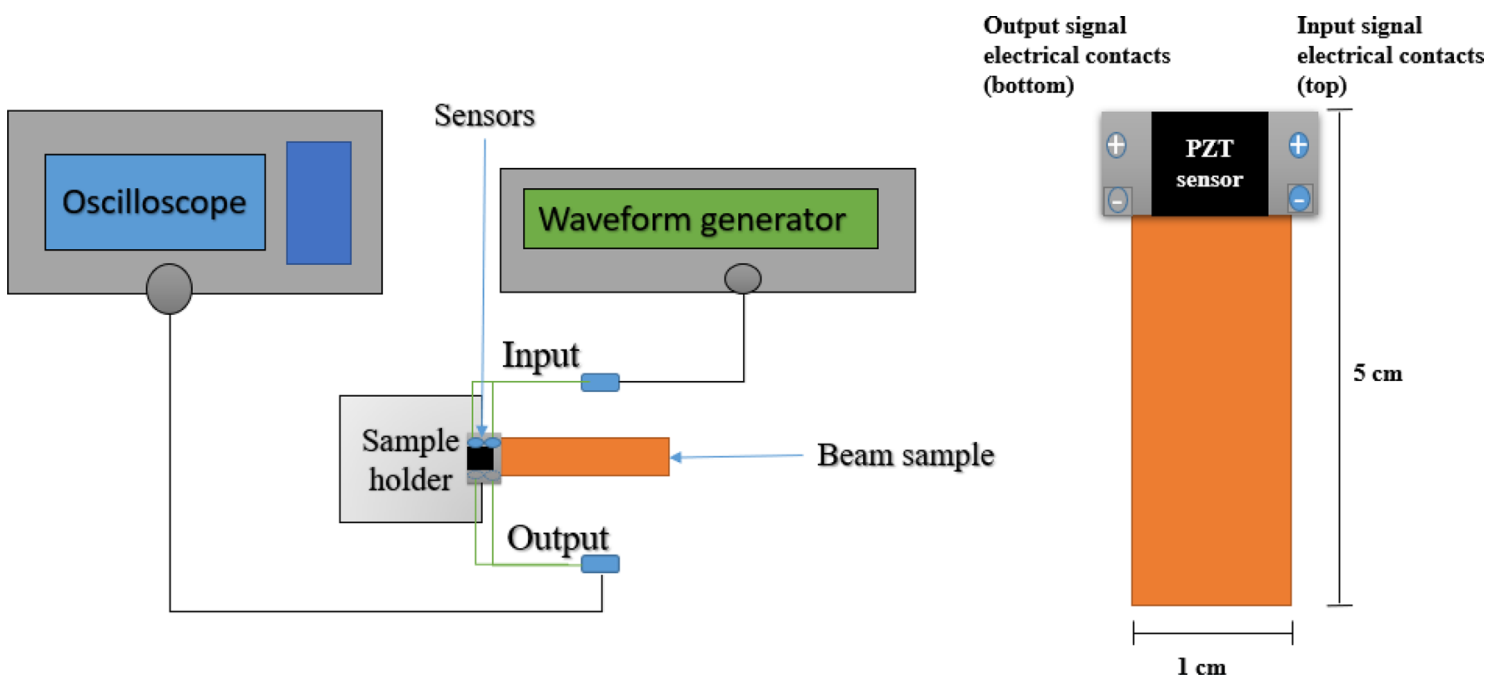

Fig. 2 Schematic of the experimental setup for damping performance testing 
temperature and $600^{\circ} \mathrm{C}$. At $750^{\circ} \mathrm{C}$, the preferred orientation was found to be (111) type. The reason for the change in orientation from (200) to (111) is associated with higher adatom mobility at a higher temperature that results in the formation of surfaces with lower surface energy [31]. As seen in the XRD patterns, the (200) peak is the most intense for the TiN film grown at $600^{\circ} \mathrm{C}$. The appearance of diffraction peaks with mixed $h, k$, and I values indicates the random crystalline orientation in the films, which can be attributed to a large mismatch $(\sim 30 \%)$ in lattice constants of TiN ( $4.22 \AA$ ) films and Ti ( $2.95 \AA$ ) substrates.

In another set of PLD experiments, the ambient nitrogen pressure was maintained at 50 and 100 mTorr keeping the substrate temperature fixed at $600^{\circ} \mathrm{C}$. XRD patterns for these TiN films are shown in Fig. 4. Shown for comparison in this figure is also the XRD pattern recorded from the TiN film that was grown in a vacuum $\left(\sim 4-5 \times 10^{-6} \mathrm{Torr}\right)$ at $600^{\circ} \mathrm{C}$. These patterns again indicate peaks that correspond to the (220) and (222) planes of TiN. However, there is a shift in the peak position of the (200) plane and the majority of the substrate peaks are not visible in the nitrogen content samples as opposed to peaks seen in Fig. 3. The shift in the peak positions could be associated with lattice strain caused by the nitrogen atoms acting as impurities due to overdoing and altering the structure [32,33]. Careful indexing of the peaks in Fig. 4 suggests the presence of a small amount of an alpha phase $\left(a-\mathrm{Ti}_{2} \mathrm{~N}\right)$ in the samples deposited in the nitrogen ambient; this phase is absent in the samples deposited in a vacuum. The full width half maximum (FWHM) of the most intense XRD peak and its corresponding d-values obtained from the patterns in Figs. 3 and 4 were used to calculate the lattice parameter and crystallite size of TiN coatings, respectively. The results of the lattice parameter and crystallite size calculations are displayed

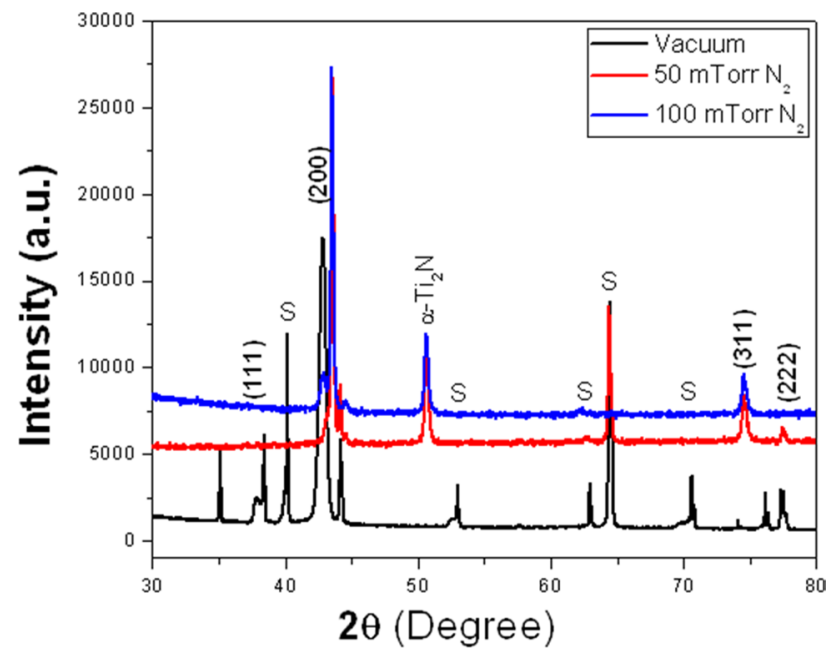

Fig. 4 XRD pattern of TiN grown on titanium disks in vacuum and nitrogen ambient in Table 1. The lattice constant decreased as the substrate temperature was increased or nitrogen was introduced during TiN film disposition. The crystallite sizes also increased when the deposition temperature increased in a vacuum. The crystallite size for nitrogen ambient samples decreased from $43 \mathrm{~nm}$ to $39 \mathrm{~nm}$ when the pressure of nitrogen ambient changes from 50 to 100 mTorr. The decrease in crystallite size with an increase in nitrogen pressure during film deposition is attributed to reduced surface diffusion of TiN species on the substrate surface.

\subsection{Adhesion test}

The adhesion test of thin-film coatings on the substrate is of paramount importance in many diverse technologies and industries. The adhesion strength of TiN coatings on Ti substrate was performed according to the standard of American Society for Testing Materials (ASTM) [34]. An ASTM-D3359-17 tape test [34] was used to observe the adhesion of TiN coatings using cross-cut patterns through the coating. Optical images of the patterns were taken using a high-resolution microscope camera (AxioCam MRc5, Carl Zeiss). The results obtained using the tape test are shown in Fig. 5. As seen in the optical images, the entire coating remains intact after the removal of the tape from the sample. This indicates that the TiN coating has strong adhesion to the Ti beam substrate.

\subsection{Potentiodynamic polarization and electrochemical impedance spectroscopic analysis}

The potentiodynamic polarization measurements of uncoated Ti substrates and TiN coated Ti substrates are shown in Figs. 6 and 7. The corrosion current densities $\left(I_{\text {corr }}\right)$ and corrosion potentials $\left(E_{\text {corr }}\right)$ of all samples were determined from the respective abscissa and ordinate values at the intersection point of anodic and cathodic curve extrapolation, as demonstrated in the inset of Fig. 6. The $I_{\text {corr }}$ and $E_{\text {corr }}$ values extracted from Figs. 6 and 7 are listed in Table 2. It is clear from these results that

Table 1 Structural parameters of the TiN coated samples under different deposition parameters

\begin{tabular}{lll}
\hline Sample name & Lattice constant $(\AA)$ & $\begin{array}{l}\text { Crystal- } \\
\text { lite size } \\
(\mathrm{nm})\end{array}$ \\
\hline TiN-RT-Ti-Vacuum & 4.31 & 12.64 \\
TiN-600-Ti-Vacuum & 4.22 & 14.91 \\
TiN-750-Ti-Vacuum & 4.25 & 22.58 \\
TiN-600-50N $2-T i$ & 4.22 & 42.77 \\
TiN-600-100N $2-T i$ & 4.17 & 38.88 \\
\hline
\end{tabular}



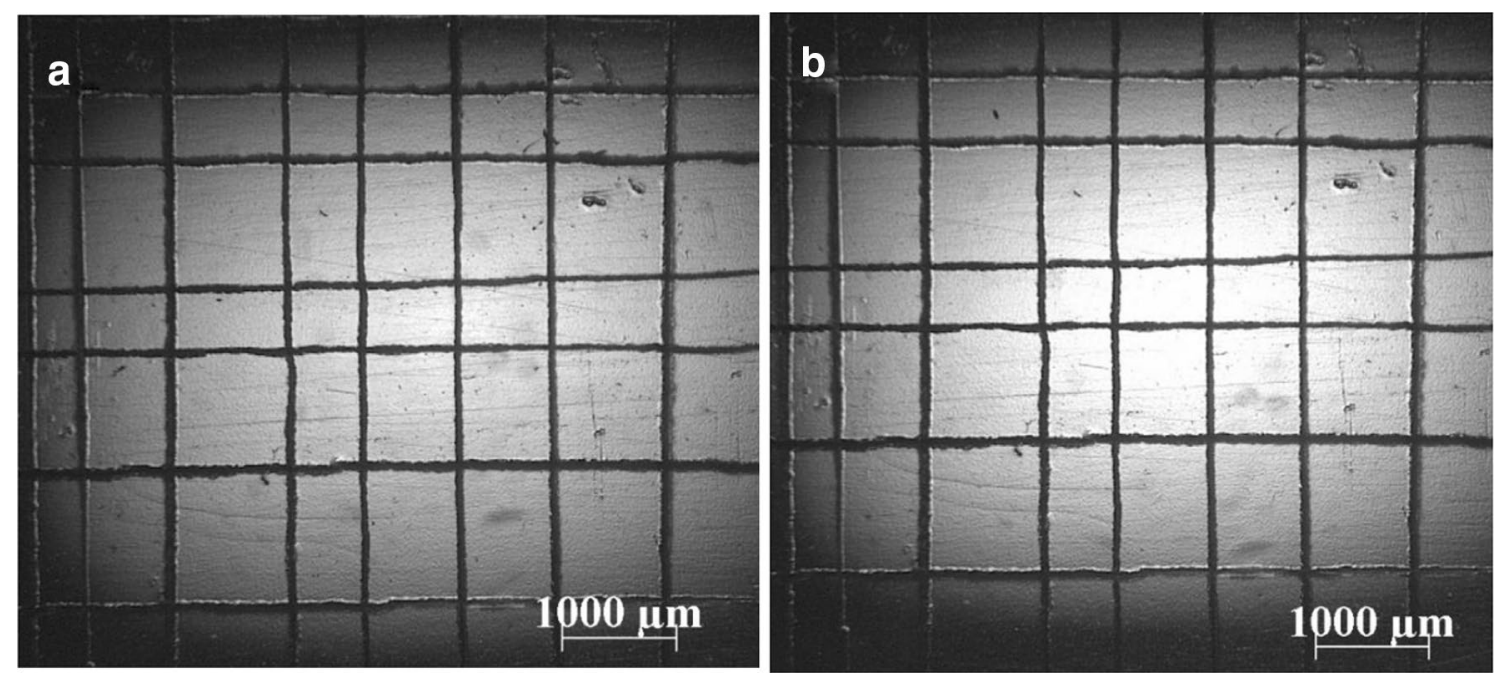

Fig. 5 Optical images of the TiN coating deposited at $750^{\circ} \mathrm{C}$ in the vacuum $\mathbf{a}$ before and $\mathbf{b}$ after the adhesion test

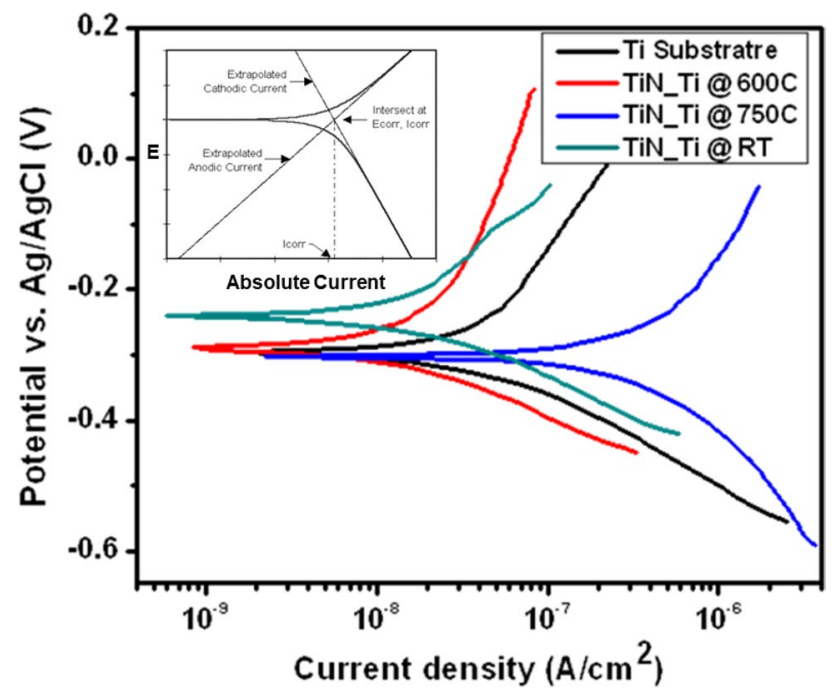

Fig. 6 Potentiodynamic polarization curves for TiN coatings at different temperatures on titanium substrates and uncoated titanium substrates simulated in PBS

TiN coatings exhibit better corrosion resistance than bare Ti disks in terms of lower current densities and less negative corrosion potentials. It is worth a note that $\mathrm{Ti}$ itself is highly corrosion-resistant metal as it lies towards the top of the electrochemical series [35]. It is well-known from the hierarchy in the electrochemical series with gold sitting at the top that the less negativepotential materials possess, the less corrosive (or nobler) the materials will be [36]. The data in Table 2 also point out that TiN coating deposited at room temperature is more cathodic compared to the coatings at $600^{\circ} \mathrm{C}$ and $750^{\circ} \mathrm{C}$. It suggests that the room temperature TiN coated Ti substrate will have less tendency to lose its electrons

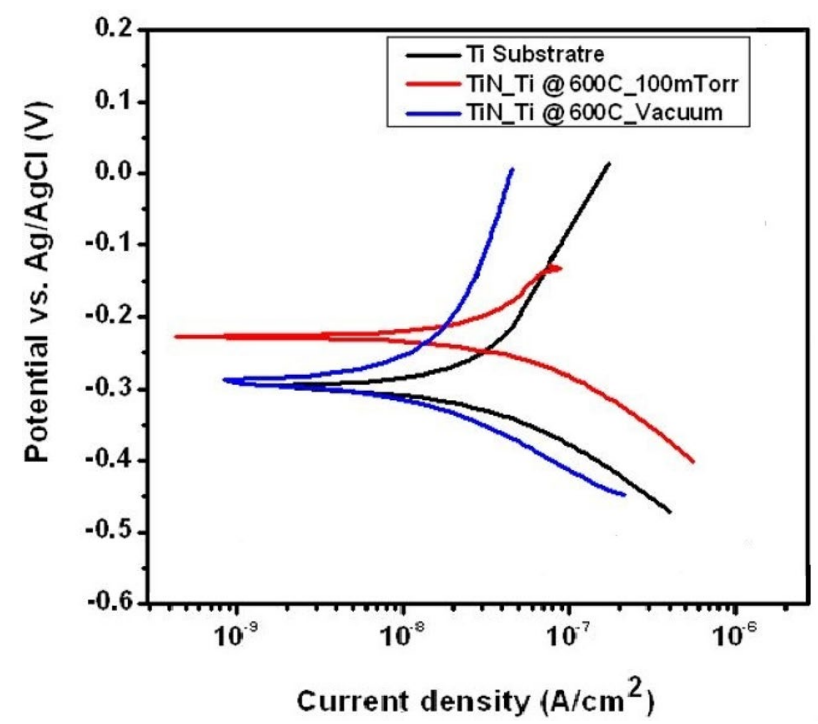

Fig. 7 Potentiodynamic polarization curves for TiN coatings deposited at $600{ }^{\circ} \mathrm{C}$ in a vacuum, $600{ }^{\circ} \mathrm{C}$ in 100 mTorr of nitrogen and uncoated titanium substrates

and thus will be more corrosion resistive compared to TiN coatings at the higher temperature. The corrosion properties of TiN coating become even nobler when the TiN deposition is carried out in the presence of $100 \mathrm{mTorr}$ nitrogen at $600{ }^{\circ} \mathrm{C}$, though its corrosion current density is marginally higher than room temperature coated TiN sample. The corrosion protective nature of the TiN coatings was further analyzed based on protection efficiency. The protection efficiency (PE) of the TiN coatings on the Ti disks was estimated using the equation given below [37]:

\section{SN Applied Sciences}


Table 2 Corrosion current densities $\left(\boldsymbol{I}_{\text {corr }}\right)$, corrosion potentials $\left(\boldsymbol{E}_{\text {corr }}\right)$, and polarization resistance $\left(R_{p}\right)$ for all TiN films coated on titanium substrates and a bare Ti substrate

\begin{tabular}{llllcc}
\hline Sample & $\begin{array}{l}R_{p} 10^{6} \\
\left.(\mathrm{Ohm} \mathrm{cm})^{2}\right)\end{array}$ & $\begin{array}{l}I_{\text {corr }} 10^{-9} \\
\left(\mathrm{~A} \mathrm{~cm}^{-2}\right)\end{array}$ & $E_{\text {corr }}(\mathrm{V})$ & $\Delta G^{\circ}\left(\mathrm{kJ} \mathrm{mol}^{-1}\right)$ & $\begin{array}{c}\text { Protection } \\
\text { efficiency (\%) }\end{array}$ \\
\hline Ti_Substrate & 1.60 & 61.1 & -0.298 & -115.01 & - \\
TiN_RT_Vacuum & 3.04 & 16.7 & -0.241 & -93.01 & 72.667 \\
TiN_600 ${ }^{\circ} \mathrm{C}$ Vacuum & 4.29 & 22.1 & -0.291 & -112.31 & 63.829 \\
TiN_750 ${ }^{\circ} \mathrm{C}$ Vacuum & 0.49 & 283 & -0.302 & -116.55 & -363.175 \\
TiN_600 ${ }^{\circ} \mathrm{C}$-100 mTorr_N & 1.05 & 46.3 & -0.227 & -87.61 & 24.222 \\
\hline
\end{tabular}

(ii)

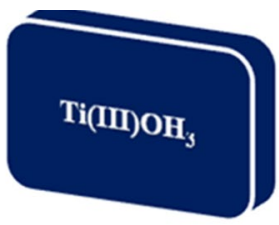

(iii)

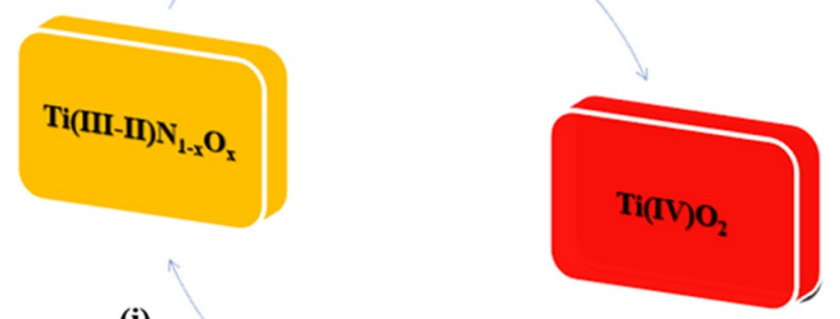

(i)

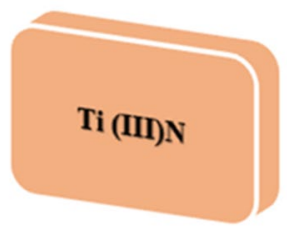

$$
\mathrm{TiN}+2 \mathrm{H}_{2} \mathrm{O} \rightarrow \mathrm{TiO}_{2}+\frac{1}{2} \mathrm{~N}_{2}+4 \mathrm{H}^{+}+4 e^{-}
$$

Fig. 8 A sequential three-step oxidation process of titanium nitride films

$\operatorname{PE}(\%)=\frac{\left(i_{\text {corr }}-i_{\text {corr }}^{\prime}\right)}{i_{\text {corr }}} \times 100$

where $i_{\text {corr }}$ and $i_{\text {corr }}^{\prime}$ are the corrosion current densities of the uncoated Ti disk and TiN coated Ti disks, respectively. The protection efficiency of TiN coated at room temperature was the highest among the others. The protection efficiency for all the TiN coatings is listed in Table 2 for comparison.

The anti-corrosion property of TiN coating is attributed primarily to its oxidation resistance behavior, which in turn, arises from its stable electronic structure brought about by strong interactions between Ti $3 d$ and N $2 p$ orbitals [38]. A sequential three-step process, shown schematically in Fig. 8 , is used to describe the potentiodynamic oxidation of TiN [38]: (1) oxygen diffuses into the TiN lattice replacing partially some of the nitrogen $(\mathrm{N})$ atoms with oxygen $(\mathrm{O})$, forming a protective $\mathrm{TiN}_{1-x} \mathrm{O}_{x}$ layer, (2) at higher potential, the $\mathrm{TiN}_{1-x} \mathrm{O}_{x}$ oxynitride layer converts to $\mathrm{Ti}(\mathrm{OH})_{3}$ hydroxide layer, and finally (3) further oxidation of the $\mathrm{Ti}(\mathrm{OH})_{3}$ takes place at the higher potential to form a more robust protective layer of $\mathrm{TiO}_{2}$. The overall reaction is also shown in Fig. 8 $[38,39]$. The standard Gibbs free energy $\left(\Delta G^{0}\right)$, calculated using the overall reaction and relation $\Delta G^{0}=n E^{0} F$, was found to be in the range of -87.61 to $-116.55 \mathrm{~kJ} \mathrm{~mol}^{-1}$ at $\mathrm{pH}$ 7.4. In this relation, $n$ is the number of electrons involved in the reaction, $E^{\circ}$ is standard electrochemical potential, and $F$ is Faraday constant $\left(96,485 \mathrm{C} \mathrm{mol}^{-1}\right)$ [40]. It is well known that higher the negative values of $\Delta G^{0}$, more likelihood is the occurrence of that reaction. The decrease in the negative values of $\Delta G^{0}$ with TiN coating thus establishes the effectiveness of TiN coatings as an anti-corrosion material. The least negative $\Delta G^{0}$ is in the case of Ti-beams coated with TiN layer deposited at 100 mTorr nitrogen ambient. TiN coating at room temperature also has a negative value just above the 100 mTorr nitrogen ambient coated TiN sample. A larger $\Delta G^{0}$ for TiN samples made at $750^{\circ} \mathrm{C}$ in vacuum conditions with respect to other vacuum samples suggest a deterioration in the TiN coating quality due to nitrogen deficiency in the coating. The nitrogen deficiency could be attributed to incomplete nitridation of the coating due to the predominance of nitrogen out-diffusion over nitrogen in-diffusion at elevated temperatures [41, 42]. Besides evidence of TiN oxidation reported in the literature $[35,36,38,39]$, the evidence in favor of TiN oxidation process has been obtained by our group too using $\mathrm{x}$-ray photoelectron spectroscopy and has been published separately [43].

The corrosion protective nature of TiN coatings was further analyzed by the EIS study. The EIS study was performed in the frequency range of $0.1-10^{4} \mathrm{~Hz}$ under $10 \mathrm{mV}$ amplitude of the perturbation signal. The EIS technique gives information about the corrosion efficiency of coatings to be obtained by measuring the changes in impedance as a function of coating materials $[37,44,45]$. Figure 9 shows Nyquist and Bode plots of the uncoated Ti substrate and Ti substrate coated with TiN thin films at an applied potential corresponding to the value of the open-circuit potential. Nyquist plots in Fig. 9a show that TiN coated Ti substrates have arcs with a larger radius of the curvature in comparison to the uncoated Ti substrate. Both the real impedance $\left(Z_{\text {real }}\right)$ and imaginary impedance $\left(Z_{\text {imag }}\right)$ for TiN coating at room 

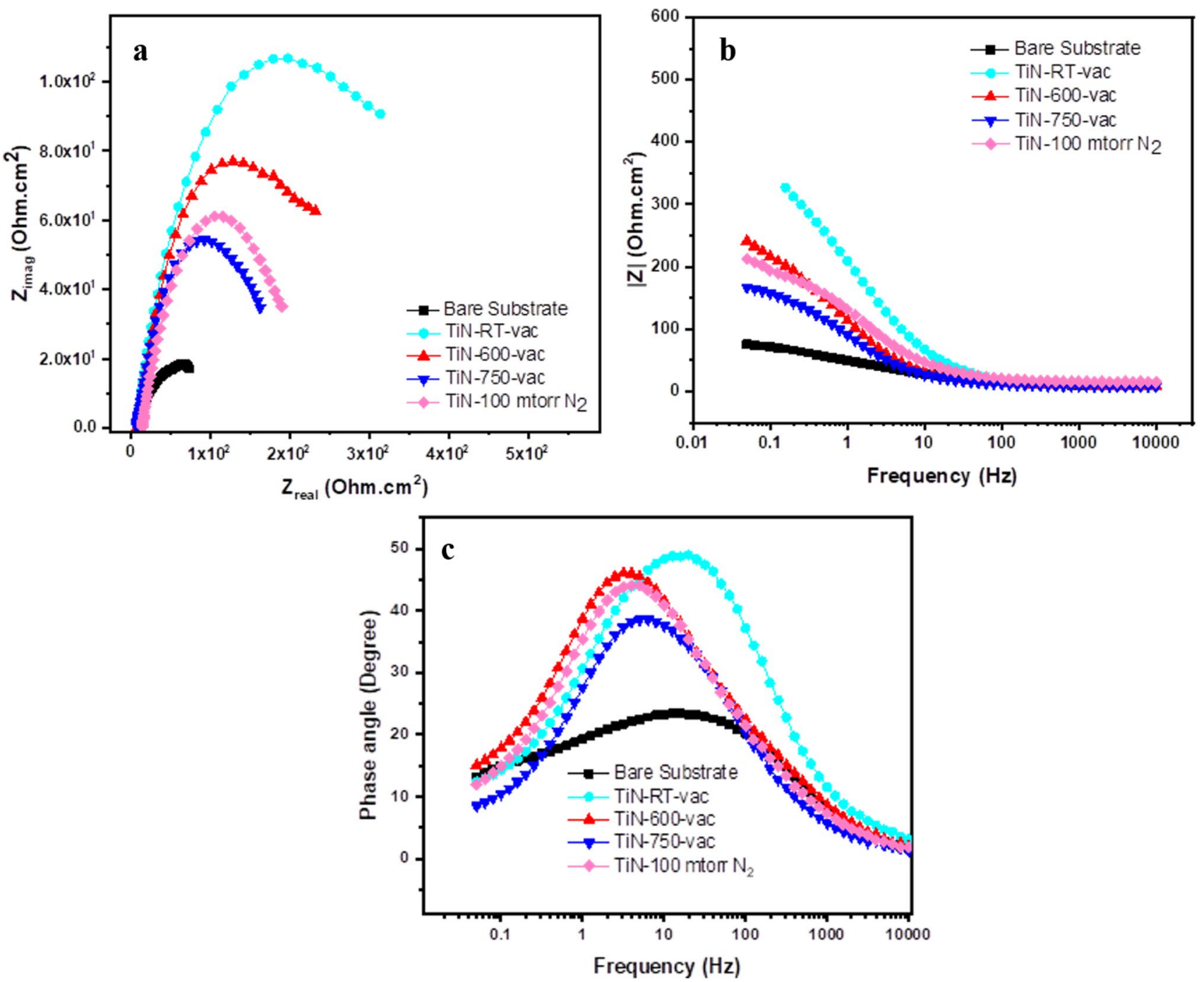

Fig. 9 Nyquist plot (a), |Z| vs. logf (b), and phase angle vs. logf plots (Bode plots) (c) for different TiN coatings on Ti substrates

temperature are higher among other samples. The higher impedance of TiN coating at room temperature prevents the diffusion of the electrons and ions from the solution to the Ti substrate and thus improves its corrosion efficiency. The observed EIS results are in a good correlation with the results obtained using the potentiodynamic polarization study. The maximum corrosion protection of TiN at room temperature is also confirmed by the largest value of $|Z|$ in the Bode plot in Fig. 9b. From Fig. 9c, a greater flattening of the maximum for TiN at room temperature indicates greater compactness of the TiN coating on the Ti substrate.

To understand the corrosion process of the uncoated $\mathrm{Ti}$ substrate and TiN-coated Ti substrates in greater detail, the surface morphology of samples was analyzed using SEM. The surface morphology of each sample was recorded before and after each corrosion test. The results obtained are presented in Fig. 10. A comparison of the SEM images in Fig. 10a, b, which represent the surface morphologies before and after the corrosion test, respectively, show that a bare Ti substrate has undergone considerable pitting and crevice corrosion that accelerates the degradation of the $\mathrm{Ti}$ substrate. We have also recorded the SEM images of other samples before and after the electrochemical corrosion tests. The results are presented in Fig. 10c through j. The image on the left is the surface morphology before and the image on the right is the surface morphology of the same sample after the electrochemical corrosion tests in each row of this image. We can see indications of fine pits caused by the corrosion. However, the number as well as the size of corrosion pits are much reduced in the TiN-coated beams with respect to the uncoated beams. The TiN coating deposited at room temperature shows the formation of a least number of corrosion pits (Fig. 10d) demonstrating the best corrosion properties of this film which matches 

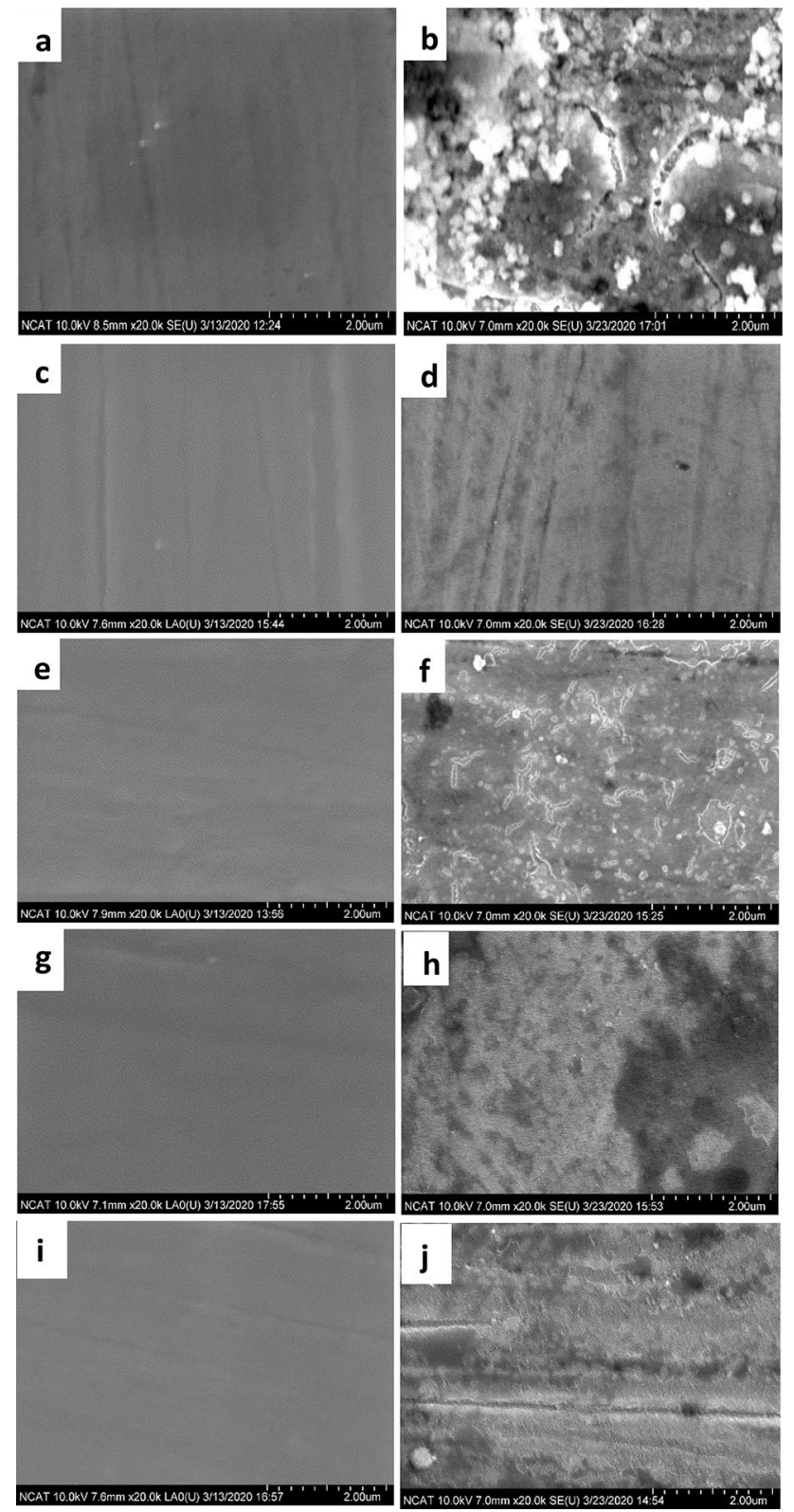

Fig. 10 SEM images of uncoated Ti substrate (a) before and (b) after corrosion; TiN coated at room temperature Ti substrate (c) before and (d) after corrosion; TiN coated at $600^{\circ} \mathrm{C}$ in vacuum (e) before and (f) after corrosion; TiN coated in $750^{\circ} \mathrm{C}$ in vacuum $(\mathbf{g})$ before corrosion and (h) after corrosion; and TiN coated at $600^{\circ} \mathrm{C}$ in 100 mTorr $\mathrm{N}_{2}$ (i) before and (j) after corrosion

with our electrochemical impedance spectroscopy (EIS) results. It is undestable that the electrochemical polarization measurements could have been done at body temperature which is usually $37^{\circ} \mathrm{C}$. The room temperature corrosion measurements were followed due to convenience and were also in accordance with the procedures followed in many reports. Besides, a simple dip-test of samples in the PBS at $27^{\circ} \mathrm{C}$ and $37^{\circ} \mathrm{C}$ have shown no difference in the surface morphology as see in Fig. 11 for one of the samples.

\subsection{Mechanical properties and damping analysis}

Shown in Fig. 12a, b are the Young's modulus of elasticity and the hardness for TiN films deposited on titanium substrates under different deposition parameters, respectively, along with modulus and hardens data of uncoated Ti substrates. Elastic modulus and hardness both follow a similar trend of increasing with temperature and slightly increased with the presence of nitrogen. The hardness enhancement at a higher temperature may be due to the existence of impurities like oxygen which can form $\mathrm{TiN}_{\mathrm{x}} \mathrm{O}_{1-\mathrm{x}}$ and inhibit the dislocation movement $[36,46]$. The average elastic modulus of the TiN coated films increases when the deposition temperature increases. There is also a slight decrease in the elastic modulus of the TiN sample that was deposited in the presence of nitrogen. The elastic modulus of the bare titanium substrate was roughly $120 \mathrm{GPa}$, and the average elastic modulus values of the TiN coated films ranged from 127 to $205 \mathrm{GPa}$. As seen in Fig. 12b, the hardness of the bare titanium substrate was roughly $4.85 \mathrm{GPa}$, and the hardness of the TiN films was in the range of $7.22-16.45 \mathrm{GPa}$. Figure $12 \mathrm{~b}$ also indicates that the hardness increases when the deposition temperature increases. There is a slight decrease in the hardness in the presence of nitrogen since the nitrogen samples were less dense and more porous.

Damping performance of TiN films, which was the primary interest of our research, was investigated by carefully monitoring the decay in wave amplitude of vibrations generated on both uncoated- and TiN-coated Ti beams. The vibrational behaviors of uncoated and TiNcoated Ti beams are shown in Fig. 13 as a function of film thickness and in Fig. 14 as a function of time. The decay $(\delta)$ parameter of each sample was calculated using Eq. (4):

$\delta=\frac{1}{n} \ln \left(\frac{X(t)}{X(t+n T)}\right)$

where $n$ is an integer number of successive (positive) peaks, $T$ is the period of oscillation, $X(t)$ is an amplitude at the time $t$, and $X(t+n T)$ is an amplitude at the time $t+n T$. From this decay parameter, the damping ratio $(\zeta)$ of each sample was calculated using Eq. (5) [10]. The results obtained are plotted in Fig. 13. In our calculation, we have used amplitudes of 4 th and 15th peak as $X(t)$ and $X(t+15 T)$, respectively.

$$
\zeta=\frac{\delta}{\sqrt{4 \pi^{2}+\delta^{2}}}
$$

The damping measurements were repeated five times on each sample. The average damping ratio for Ti beams coated with a TiN layer deposited for $180 \mathrm{~min}$ (named as Ti180TiN ${ }^{+}$) was found to be the highest $(0.0274)$ among all the samples studied here. The oscillation of this sample $\left(\mathrm{Ti}_{180 \mathrm{TiN}}{ }^{+}\right)$was found to decay fastest among all the samples. This sample 

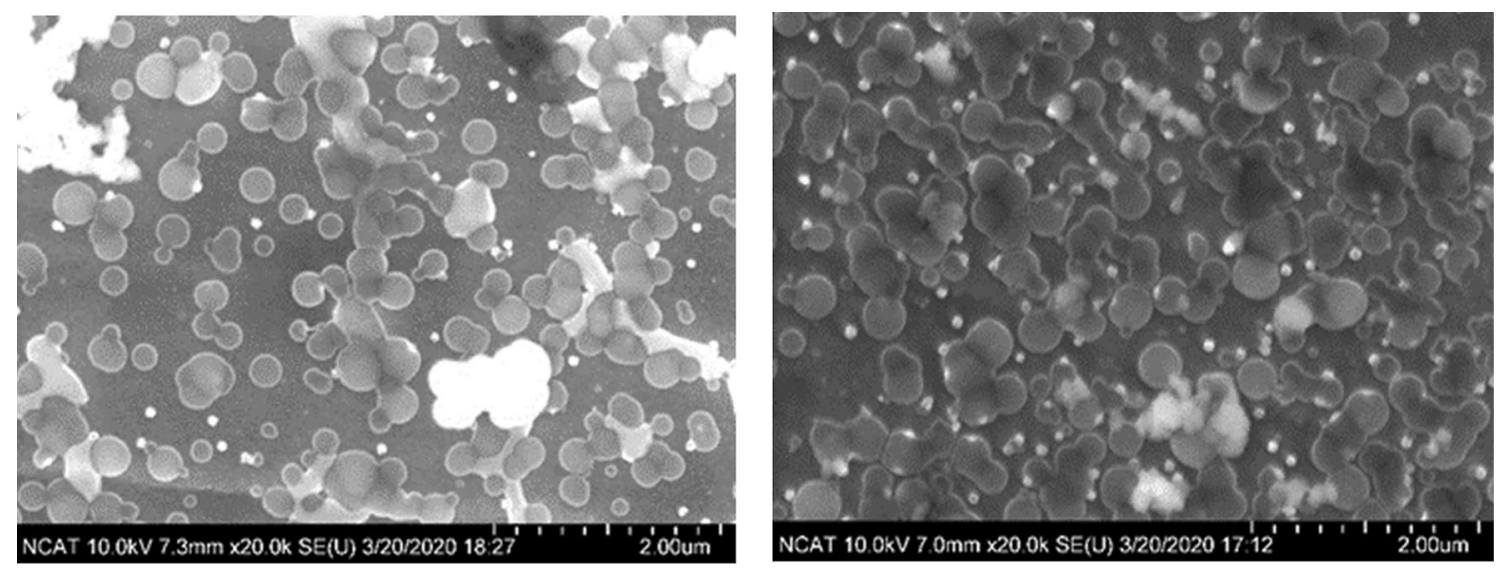

Fig. 11 SEM image of a TiN coating sample deposited at $600^{\circ} \mathrm{C}$ in vacuum after dipping the sample for $24 \mathrm{~h}$ in a PBS solution at a $27^{\circ} \mathrm{C}$ and b $37^{\circ} \mathrm{C}$

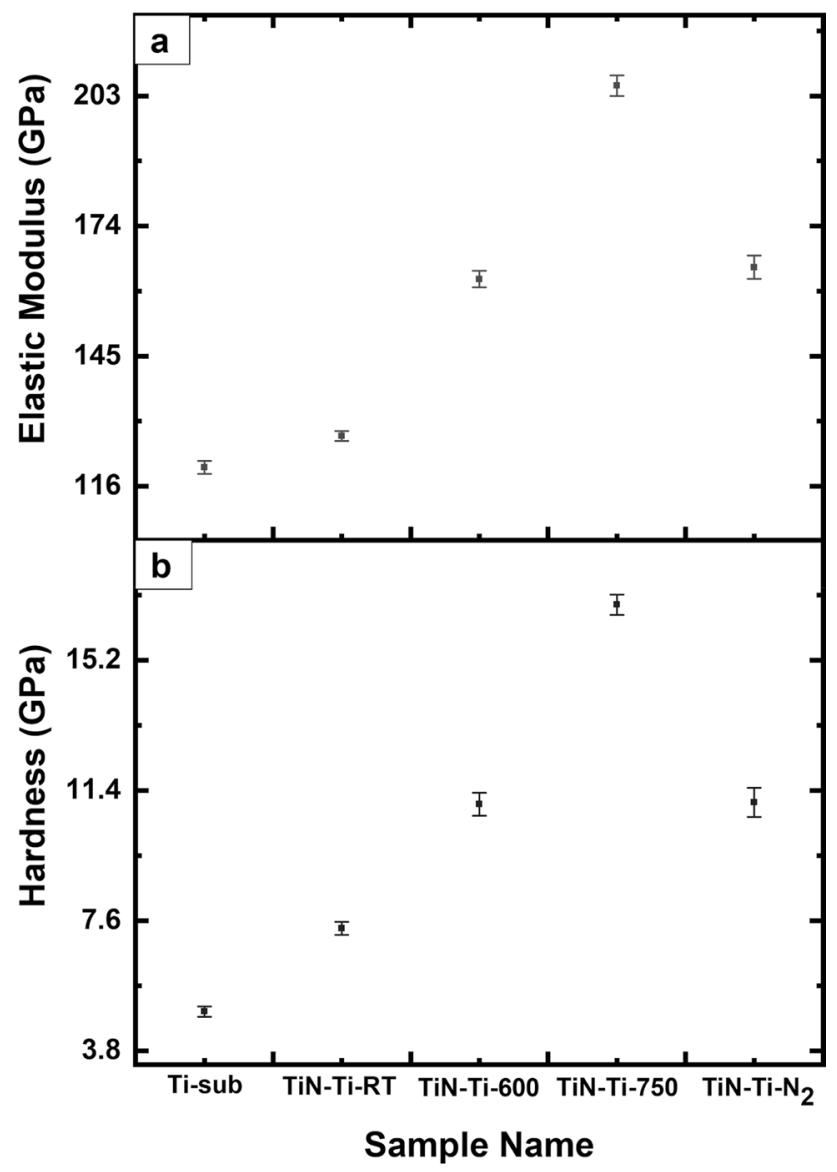

Fig. 12 Average hardness (a) and average elastic modulus (b) results for TiN deposited on titanium disks at different temperatures $\left(\mathrm{RT}, \sim 30^{\circ} \mathrm{C}\right), 600^{\circ} \mathrm{C}$, and $750^{\circ} \mathrm{C}$ and nitrogen pressure

had an intermediate coating of a thin layer of pure Ti which was provided to increase the TiN coating adhesion to Ti beams. The decays of vibration amplitudes in the samples that were prepared by depositing TiN for $180 \mathrm{~min}$ and

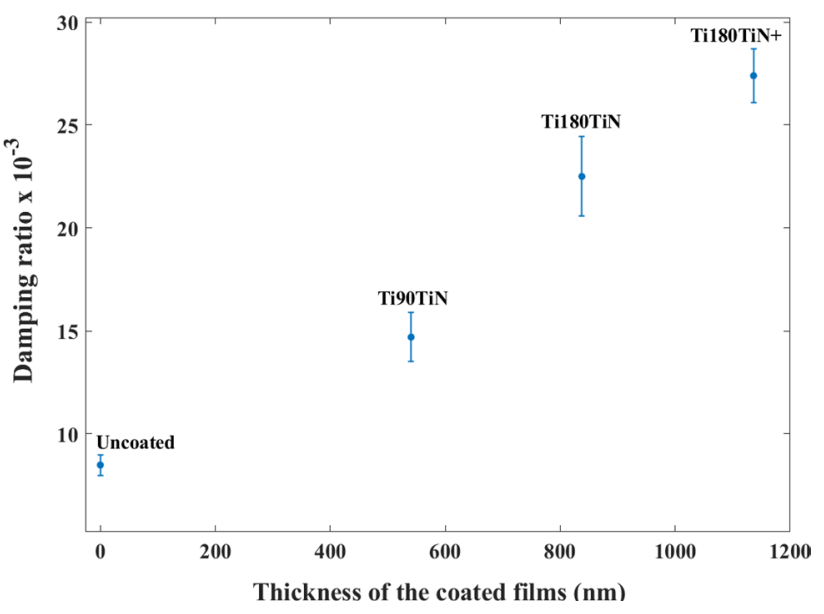

Fig. 13 Relation between average damping ratio and thickness of the coatings, namely, uncoated, $1.5 \mathrm{~h}$-coated TiN (Ti90TiN), 3 h-coated TiN (Ti180TiN), and 3 h-coated TiN +10 min Ti layer (Ti180TiN+), respectively

$90 \mathrm{~min}$, labeled Ti180TiN and Ti90TiN, respectively, were found to be slower with respect to $\mathrm{Ti}_{180 \mathrm{TiN}}{ }^{+}$sample, but faster with respect to the uncoated Ti beam. Figure 13 shows that the average damping ratio value of the $\mathrm{Ti}_{180 \mathrm{TiN}}{ }^{+}$coated sample (0.0274) is about two orders of magnitude (223\%) higher with respect to the uncoated Ti beam which has an average damping ratio of 0.00848 . For the $3-\mathrm{h}$ TiN-coated $(\mathrm{Ti} 180 \mathrm{TiN}$ ) (average damping ratio $=0.0225$ ) and $1.5-\mathrm{h}$ TiNcoated (Ti90TiN) (average damping ratio $=0.0147$ ) Ti-beams, their average damping ratio values indicate $165 \%$ and $73 \%$ improvements in comparison to the uncoated Ti-beams, respectively. Thus, these results have demonstrated that TiN thin film coatings can significantly improve the vibration damping capability of the bare Ti beams.

The quality factor $(Q)$ measured using the relation [3] $Q=\frac{1}{2 \xi}$ was used to further assess the damping behavior of

\section{SN Applied Sciences}


Table 3 Comparison of the damping results between uncoated beam versus TiNcoated beams

\begin{tabular}{lcll}
\hline Sample & Damping ratio $(\xi)$ (average) & Quality factor $(Q)$ & Loss factor $(\eta)$ \\
\hline Uncoated & $0.00848 \pm 0.000496$ & 58.96 & 0.01696 \\
Ti90TiN & $0.0147 \pm 0.00118$ & 34.01 & 0.0294 \\
Ti180TiN & $0.0225 \pm 0.00194$ & 22.22 & 0.0450 \\
Ti180TiN $^{+}$ & $0.0274 \pm 0.00130$ & 18.25 & 0.0548 \\
\hline
\end{tabular}

Fig. 14 Damping performance comparison of the average amplitude responses in coated and uncoated beams, namely, uncoated, 1.5 h-coated TiN (Ti90TiN), 3 h-coated TiN (Ti180TiN), and $3 \mathrm{~h}$-coated $\mathrm{TiN}+10 \mathrm{~min}$ Ti layer (Ti180TiN+), respectively

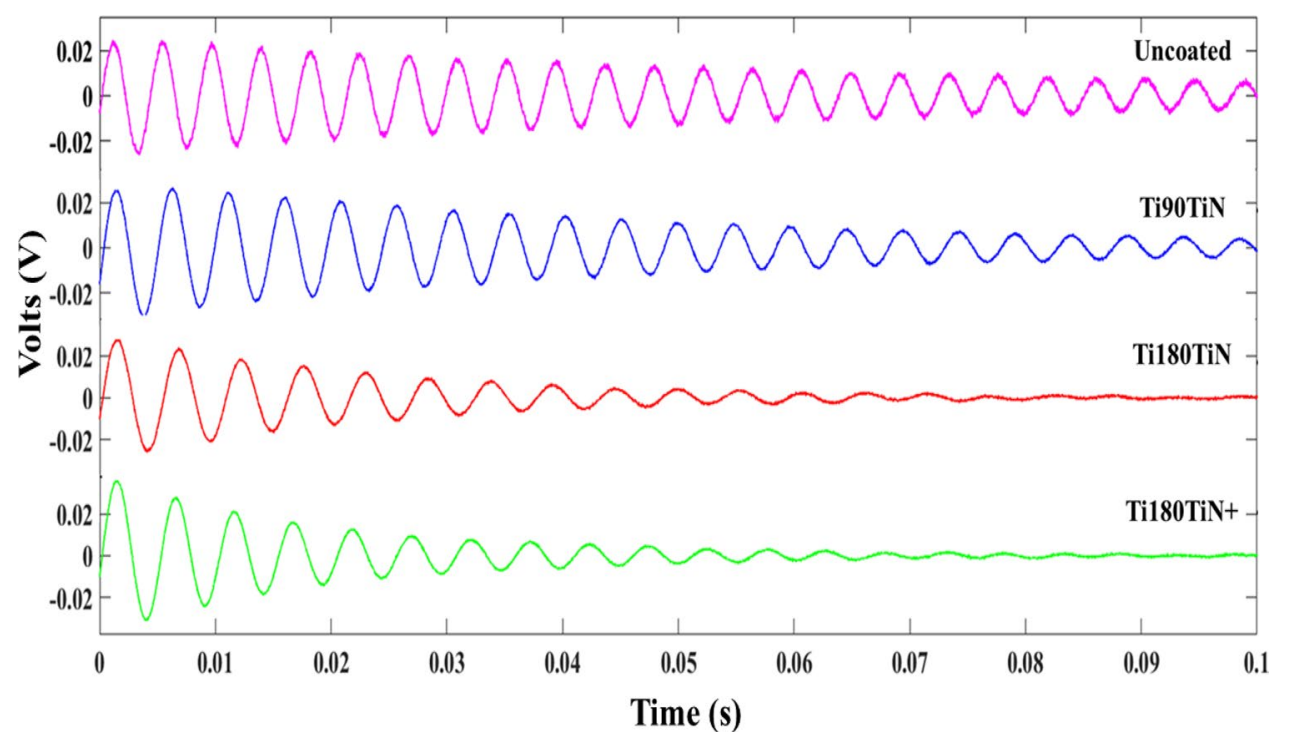

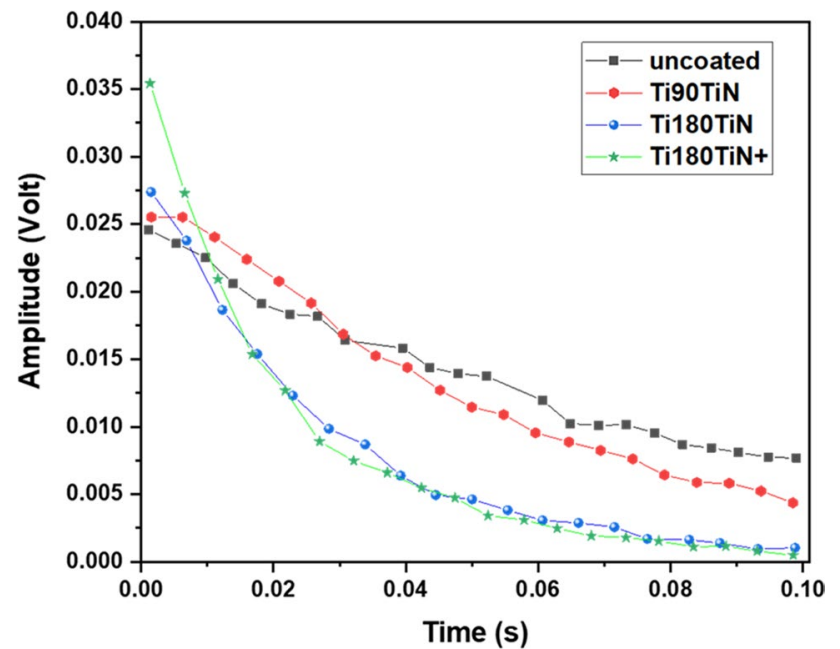

Fig. 15 Average amplitude values of the output vibration signals in each sample, namely, uncoated, $1.5 \mathrm{~h}$-coated TiN (Ti90TiN), 3 h-coated TiN (Ti180TiN), and 3 h-coated TiN +10 min Ti layer (Ti180TiN+), demonstrating their decay as a function of time
Ti beams coated with TiN layers $[3,8]$. Then taking the inverse of $Q$, the loss factor $(\eta)$ was calculated, where $\eta=1 / Q$ [8]. The loss factor reflects the energy dissipated in a unit volume of material during one complete cycle of oscillation at a particular combination of temperature and amplitude oscillatory strain [8]. Thus, a good damping material should dissipate more energy i.e., the material should have higher $\eta$ and lower $Q$ values [3]. From the values of $\eta$ listed in Table 3, it is clear that TiN-coated beams dissipate more energy than the bare Ti beam as their $\xi$ values are larger and $Q$ values are smaller in comparison to those in the uncoated sample. The amount of energy dissipated during beams' vibration was determined quantitatively by finding the area under vibrational amplitude decay curves as a function of time.

These curves were generated by plotting the maximum height of each peak in Fig. 14 as a function of time. The curves were then fitted to an exponential decay of the first order in Fig. 15. The integrated area for bare Ti-beam and TiN coated Ti-beam $\left(\mathrm{Ti}_{180 \mathrm{TiN}}^{+}\right)$were $0.00139 \mathrm{~V} \mathrm{~s}$ and $0.000742 \mathrm{~V}$ s, respectively. This indicates that the integrated area of the amplitude decay in Fig. 15 is a reciprocal of the dissipation energy. The integrated area of our TiN-coated beam shows a high effective decrease in the integrated area 
Fig. 16 Surface morphology of the coated area by RF magnetron sputtering (left); Cross-section with the thickness (right) of a $540.62 \mathrm{~nm}$ (i.e., 1.5-h TiN coated beam), b $837.65 \mathrm{~nm}$ (i.e., 3-h coated beam), and c $1136.36 \mathrm{~nm} \mathrm{TiN/}$ Ti films (i.e., 3-h TiN and 10-min Ti coated beam)
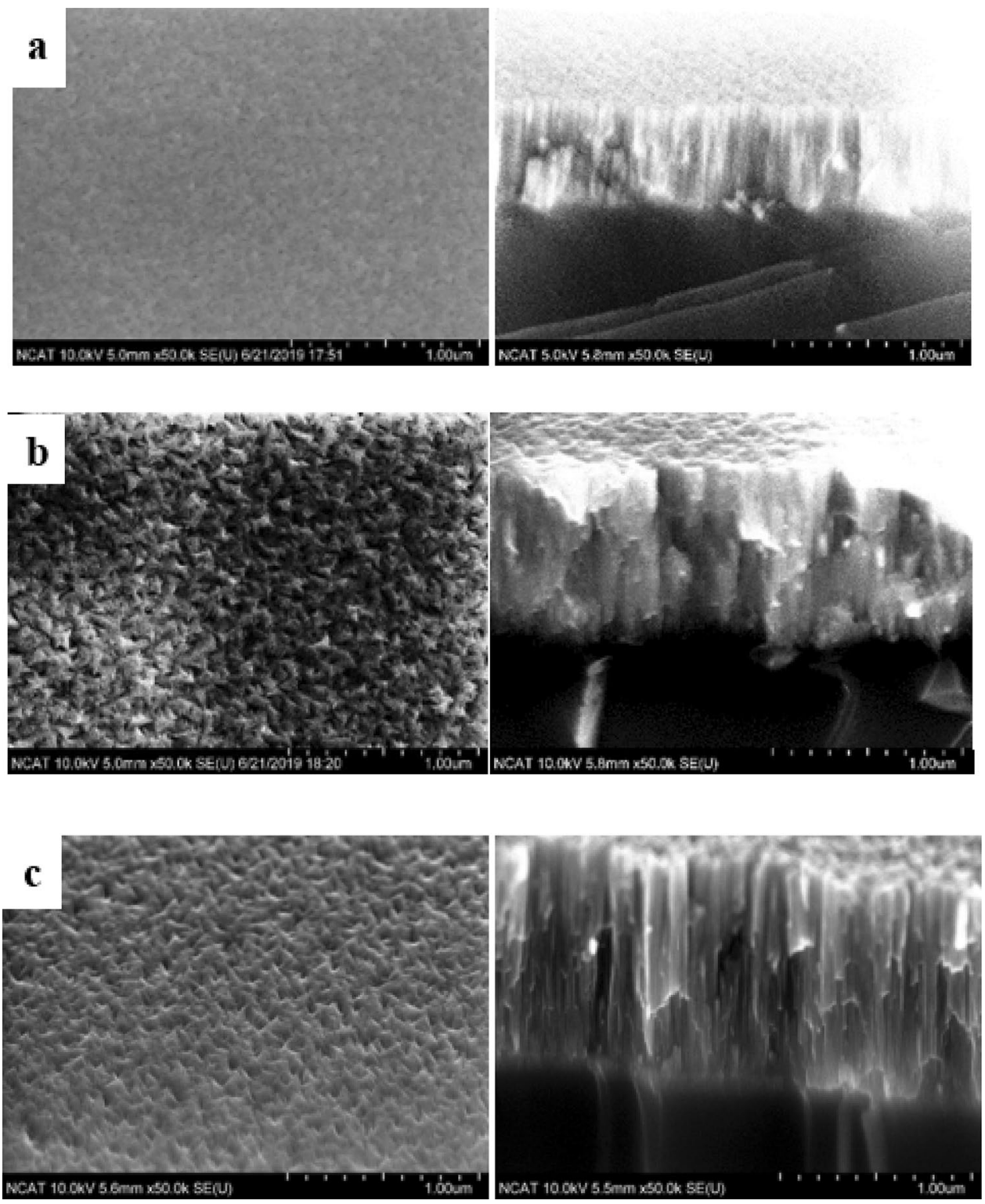

by $47 \%$ compared to the uncoated beam. This agrees with the loss factor shown in Table 3 that our TiN-coated samples have higher dissipation energy than the bare Ti-beam. The higher dissipation energy for TiN coated beams is explained on the basis of the microstructure of the polycrystalline TiN layer on a polycrystalline underlying Ti substrate. As seen in the surface and cross-sectional SEM images in Fig. 16, TiN coating is polycrystalline and has a columnar complex microstructure that consists of random voids and irregular thin lamellae formed by rapid solidification of molten TiN material on the substrate. According to Patsias et al, the internal friction between the lamellar interfaces is the primary source of energy dissipation in ceramic layers [47]. The dissipation of energy in the interfaces may also be explained by the quality of adhesion of the substrate and film, and also interfacial misfit dislocation [48]. Macro-interfaces between the coating layer and substrate, lamellar interface in the coating layer, grain boundary, and porosity have also been attributed to the improvement in the damping capability of the structures $[49,50]$.

\section{Conclusions}

Uniform and hard TiN thin film coatings have been developed on Ti by two commonly used physical vapor deposition methods. The effect of this TiN coating on Ti

\section{SN Applied Sciences}


substrates in terms of corrosion resistance and vibration damping was investigated. The coatings have been found to be favorably efficient as corrosion protection and vibration damping of titanium beams. Potentiodynamic polarization data shows that the corrosion current densities of TiN coated Ti beams have been up to six times lower with respect to uncoated-Ti beams. It is also evident from the electrochemical impedance spectroscopy that TiN coating at room temperature is the most corrosion resistive among other coatings studies in this research. Tape test reveals that TiN coating has strong adhesion to Ti substrates. The damping performance of the Ti beams was also found to be enhanced significantly by TiN film coatings. The damping ratio values of the coated beams are greater than those of the uncoated leading to the future use of TiN coatings in aerospace applications. An intermediate layer of Ti film between Ti beam and TiN coating was found to further improve the damping performance. The energy dissipation at the Ti beam-TiN coatings interface and inter-lamellae interface within TiN coatings are believed to be the mechanism responsible for reducing vibration amplitudes of TiN-coated beams.

Acknowledgements The authors would like to acknowledge the financial support from the Air Force Research Laboratory [Grant Number FA8650-17-2-2229]; NSF MRSEC at the University of Nebraska, Lincoln [Grant Numbers NSF-DMR 1420645, NSF-MPS-DMR 0820521]; and NSF Major Research Instrumentation (MRI) program [Grant Number CMMI-1040290].

\section{Compliance with ethical standards}

Conflict of interest The authors declare that they have no conflict of interest.

\section{References}

1. Al-Rub RKA, Palazotto AN (2010) Micromechanical theoretical and computational modeling of energy dissipation due to nonlinear vibration of hard ceramic coatings with microstructural recursive faults. Int J Solids Struct 47(16):2131-2142

2. Du G, Ba DC, Tan Z, Sun W, Liu K, Han Q (2013) Vibration damping performance of ZrTiN coating deposited by arc ion plating on TC4 Titanium alloy. Surf Coat Technol 229:172-175

3. Blackwell C, Palazotto A, George TJ, Cross CJ (2007) The evaluation of the damping characteristics of a hard coating on titanium. Shock Vib 14(1):37-51

4. Mehdizadeh $M$, Khonsari MM (2018) On the role of internal friction in low-and high-cycle fatigue. Int J Fatigue 114:159-166

5. Chen Y, Zhai J, Han Q (2016) Vibration and damping analysis of the bladed disk with damping hard coating on blades. Aerosp Sci Technol 58:248-257

6. Nalla R, Ritchie R, Boyce B, Campbell J, Peters J (2002) Influence of microstructure on high-cycle fatigue of Ti-6Al-4V: bimodal vs. lamellar structures. Metall Mater Trans A 33(3):899-918
7. Sun W, Liu Y (2016) Vibration analysis of hard-coated composite beam considering the strain dependent characteristic of coating material. Acta Mech Sin 32(4):731-742

8. Torvik PJ, Langley B (2015) Material properties of hard coatings developed for high damping. In: 51 st AIAA/SAE/ASEE joint propulsion conference, p 4195

9. Vega J, Scheerer H, Andersohn G, Oechsner M (2018) Experimental studies of the effect of Ti interlayers on the corrosion resistance of TiN PVD coatings by using electrochemical methods. Corros Sci 133:240-250

10. De Silva CW (2007) Vibration damping, control, and design, 1st edn. CRC Press, Hoboken

11. Patsias S, Tassini N, Stanway R (2004) Hard ceramic coatings: an experimental study on a novel damping treatment. In: Smart structures and materials 2004: damping and isolation, vol 5386. International Society for Optics and Photonics 2004, pp 174-185

12. Rongong J, Tomlinson G (2005) Amplitude dependent behaviour in the application of particle dampers to vibrating structures. In: 46th AIAA/ASME/ASCE/AHS/ASC structures, structural dynamics and materials conference, 2005. p 2327

13. Easterday O, Palazotto A, Baker W, Branam R (2017) Damping properties of coatings at elevated temperatures. Surf Coat Technol 321:186-199

14. Kong J, Zhou C, Gong S, Xu H (2003) Low-pressure plasmasprayed $\mathrm{Al}-\mathrm{Cu}-\mathrm{Fe}-\mathrm{Cr}$ quasicrystalline coating for Ti-based alloy oxidation protection. Surf Coat Technol 165(3):281-285

15. Karimi A, Giauque P, Martin JL (1996) Magnetomechanical damping in plasma sprayed iron-chromium based coatings. J Appl Phys 79(3):1670-1677

16. Tassini N, Lambrinou K, Mircea I, Patsias S, Van der Biest O, Stanway R (2005) Comparison of the damping and stiffness properties of $8 \mathrm{wt} \%$ yttria stabilized zirconia ceramic coating deposited by the APS and EB-PVD techniques. In: Smart structures and materials 2005: damping and isolation, vol 5760. International Society for Optics and Photonics, pp 109-118

17. Veiga C, Davim J, Loureiro AJR (2012) Properties and applications of titanium alloys: a brief review. Rev Adv Mater Sci 32(2):133-148

18. Peters $\mathrm{M}$, Kumpfert J, Ward CH, Leyens $\mathrm{C}$ (2003) Titanium alloys for aerospace applications. Adv Eng Mater 5(6):419-427

19. Faruque MK, Kwadwo M, Xu Z, Kumar D (2012) Fabrication, characterization, and mechanism of vertically aligned titanium nitride nanowires. Appl Surf Sci 260:36-41

20. Gbordzoe S, Mensah-Darkwa K, Gupta R, Kumar D (2013) Growth and characterization of titanium nitride nanowires on silicon substrate using pulsed laser deposition method for biological applications. In: ASME 2013 international mechanical engineering congress and exposition, 2013. American Society of Mechanical Engineers, pp V02AT02A053-V002AT002A053. https ://doi.org/10.1115/IMECE2013-64883

21. Ghasemi S, Shanaghi A, Chu PK (2017) Corrosion behavior of reactive sputtered $\mathrm{Ti} / \mathrm{TiN}$ nanostructured coating and effects of intermediate titanium layer on self-healing properties. Surf Coat Technol 326:156-164

22. Shukla K, Rane R, Alphonsa J, Maity P, Mukherjee S (2017) Structural, mechanical and corrosion resistance properties of Ti/TiN bilayers deposited by magnetron sputtering on AISI 316L. Surf Coat Technol 324:167-174

23. Datta S, Das M, Balla VK, Bodhak S, Murugesan VK (2018) Mechanical, wear, corrosion and biological properties of arc deposited titanium nitride coatings. Surf Coat Technol 344:214-222

24. Roy M, Mucha NR, Ponnam RG, Jaipan P, Scott-Emuakpor O, Yarmolenko S, Majumdar AK, Kumar D (2019) Quantum 
interference effects in titanium nitride films at low temperatures. Thin Solid Films 681:1-5

25. Chou WJ, Yu GP, Huang JH (2002) Mechanical properties of TiN thin film coatings on 304 stainless steel substrates. Surf Coat Technol 149(1):7-13

26. Liu X, Chu PK, Ding C (2004) Surface modification of titanium, titanium alloys, and related materials for biomedical applications. Mater Sci Eng: R: Rep 47(3-4):49-121

27. Subramanian B, Muraleedharan C, Ananthakumar R, Jayachandran M (2011) A comparative study of titanium nitride (TiN), titanium oxy nitride (TiON) and titanium aluminum nitride (TiAIN), as surface coatings for bio implants. Surf Coat Technol 205(21-22):5014-5020

28. Cui W, Qin G, Duan J, Wang H (2017) A graded nano-TiN coating on biomedical Ti alloy: low friction coefficient, good bonding and biocompatibility. Mater Sci Eng C 71:520-528

29. van Hove RP, Sierevelt IN, van Royen BJ, Nolte PA (2015) Titanium-nitride coating of orthopaedic implants: a review of the literature. Biomed Res Int. https://doi.org/10.1155/2015/48597 5

30. Twite R, Bierwagen GP (1998) Review of alternatives to chromate for corrosion protection of aluminum aerospace alloys. Prog Org Coat 33(2):91-100

31. Guo H, Chen W, Shan Y, Wang W, Zhang Z, Jia J (2015) Microstructures and properties of titanium nitride films prepared by pulsed laser deposition at different substrate temperatures. Appl Surf Sci 357:473-478

32. Gupta R, Gupta M (2005) Nanocrystallization and amorphization induced by reactive nitrogen sputtering in iron and permalloy. Phys Rev B 72(2):024202. https://doi.org/10.1103/PhysR evB.72.024202

33. Höche D, Schikora $H$, Zutz $H$, Queitsch R, Emmel A, Schaaf $P$ (2008) Microstructure of TiN coatings synthesized by direct pulsed Nd: YAG laser nitriding of titanium: development of grain size, microstrain, and grain orientation. Appl Phys $A$ 91(2):305-314

34. ASTM D3359-17, Standard Test Methods for Rating Adhesion by Tape Test, ASTM International, West Conshohocken, PA, 2017, www.astm.org

35. Zhang Y, Zheng Y, Li Y, Wang L, Bai Y, Zhao Q, Xiong X, Cheng $Y$, Tang Z, Deng Y (2015) Tantalum nitride-decorated titanium with enhanced resistance to microbiologically induced corrosion and mechanical property for dental application. PLoS ONE 10(6):e0130774. https://doi.org/10.1371/journal.pone.0130774

36. Callister WD, Rethwisch DG (2015) Fundamentals of materials science and engineering an integrated approach, 5th edn. Wiley, Hoboken

37. Gupta RK, Mensah-Darkwa K, Kumar D (2014) Corrosion protective conversion coatings on magnesium disks using a hydrothermal technique. J Mater Sci Technol 30(1):47-53
38. Avasarala B, Haldar P (2010) Electrochemical oxidation behavior of titanium nitride based electrocatalysts under PEM fuel cell conditions. Electrochim Acta 55(28):9024-9034

39. Milošv I, Strehblow HH, Navinšek B, Metikoš-Huković M (1995) Electrochemical and thermal oxidation of TiN coatings studied by XPS. Surf Interface Anal 23(7-8):529-539

40. Barker D, Walsh FC (1991) Applications of Faraday's laws of electrolysis in metal finishing. Trans IMF 69(4):158-162

41. Kumar $D, A$ pte $P$, Pinto $R$ (1995) Two-dimensional growth model for laser-ablated Ag-doped $\mathrm{YBa}_{2} \mathrm{Cu}_{3} \mathrm{O}_{7-x}$ thin films. J Appl Phys 77(11):5802-5808

42. Kumar D, Sharon M, Apte P, Pinto R, Pai S, Purandare S, D'Souza C, Gupta L, Vijayaraghavan R (1994) Silver doping and its influence on the oxygenation during in situ growth of $\mathrm{YBa}_{2} \mathrm{Cu}_{3} \mathrm{O}_{7-x}$ thin films. J Appl Phys 76(2):1349-1351

43. Mucha NR, Som J, Shaji S, Fialkova S, Apte PR, Balasubramanian B, Shield JE, Anderson M, Kumar D (2020) Electrical and optical properties of titanium oxynitride thin films. J Mater Sci. https:// doi.org/10.1007/s10853-019-04278-x

44. Gupta RK, Mensah-Darkwa K, Kumar D (2013) Effect of post heat treatment on corrosion resistance of phytic acid conversion coated magnesium. J Mater Sci Technol 29(2):180-186

45. Yi P, Peng L, Huang J (2016) Multilayered TiAIN films on Ti6Al4V alloy for biomedical applications by closed field unbalanced magnetron sputter ion plating process. Mater Sci Eng C 59:669-676

46. Subramanian B, Ananthakumar R, Vidhya V, Jayachandran M (2011) Influence of substrate temperature on the materials properties of reactive DC magnetron sputtered Ti/TiN multilayered thin films. Mater Sci Eng B 176(1):1-7

47. Patsias S, Saxton C, Shipton M (2004) Hard damping coatings: an experimental procedure for extraction of damping characteristics and modulus of elasticity. Mater Sci Eng A 370(1-2):412-416

48. Colorado H, Velez J, Salva H, Ghilarducci A (2006) Damping behavior of physical vapor- deposited TiN coatings on AISI 304 stainless steel and adhesion determinations. Mater Sci Eng A 442(1-2):514-518

49. McPherson R (1989) A review of microstructure and properties of plasma sprayed ceramic coatings. Surf Coat Technol 39:173-181

50. Chen C, Lakes R (1993) Analysis of high-loss viscoelastic composites. J Mater Sci 28(16):4299-4304

Publisher's Note Springer Nature remains neutral with regard to jurisdictional claims in published maps and institutional affiliations. 